\title{
SIMULTANEOUS ELECTRICAL AND MECHANICAL RECORDING FROM POSTURAL MUSCLES IN A PARAPLEGIC PATIENT
}

\author{
By P. HARRIS and E. G. WALSH \\ Departments of Neurological Surgery and Physiology, University of Edinburgh
}

WE have recently studied a paraplegic patient, aged 28 , employed in a telephone control centre, and wish to record briefly a trick by which he can raise himself from the seated position. He thumps both thighs with his fists and there results an extensor spasm of the knees. Using this procedure he can stand with the aid of sticks or a little help from another person. Our studies of this phenomenon are at
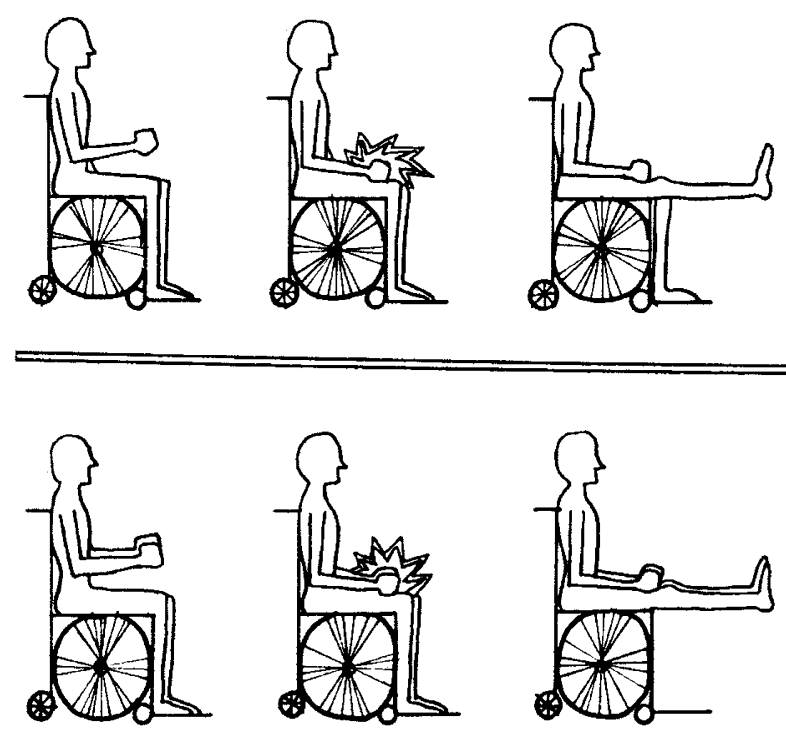

FIG. I

present incomplete, but it appears that the mechanical stimulus to the quadriceps sets up a clonic state which merges into a continuous extensor thrust. If he hits one thigh only that alone is affected (fig. I). The mechanism only works if he is lying back in his chair by some $20^{\circ}$ from the vertical. This may indicate that the rectus femoris is important in the reaction as it runs over both the hip and the knee. Surface electromyographic recordings have been made, and discharges are recorded both at flexion and at extension (fig. 2). The doubling in the activity at the upper end of the thigh acts as a 'rectifier', to use an electrical analogy. Thus movement either way may produce a contraction and the extensor state builds up.

This is an example of the way in which unexpected beneficial results may be obtained by delivering stimuli to a diseased nervous system. 


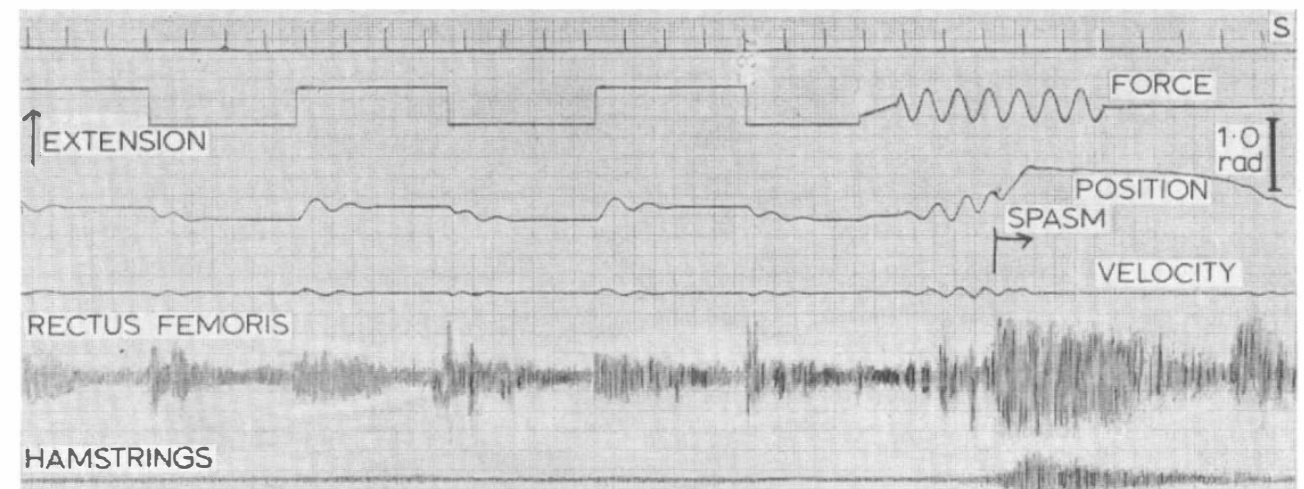

VASTUS MEDIALIS

FIG. 2

Polygraph during simultaneous electrical and mechanical recording.

Financial support for these studies has been provided by Roche Products Ltd., and by a Government Grant from the Royal Society.

\title{
HOSPITAL ACTIVITY ANALYSIS
}

\author{
By Dr. J. B. Cook, M.D., F.R.C.P. \\ Consultant Neurologist, Pinderfields General Hospital, Wakefield
}

\section{Abstract}

IN December 1968, an investigation was made into the admission of traumatic paraplegia and tetraplegia to a spinal injuries unit, using a computer under the scheme of Hospital Activity Analysis.

On checking the information provided by the computer with the notes of the patients known to have been discharged from the unit, it was found that the diagnostic information from the computer was grossly inaccurate, covering a wide field of diagnosis from epilepsy to tonsillectomy.

On comparing the computer estimate of readmissions during one year, the computer was found to be 26 per cent. in error, and in comparing the discharges of new patients during one year, the computer error was 38 per cent.

It was considered that although the difficulties of diagnostic coding are very great, the clinician must attempt to achieve accuracy.

It is thought probable that the figures provided by Hospital Activity Analysis are not sufficiently reliable to be used for purposes of planning. 